Research Article

\title{
Construction of the Evaluation System of Sustainable Utilization of Large Stadiums Based on the AHP Method
}

\author{
Li-Cai Zhu, ${ }^{1,2}$ Zhi Gao $\mathbb{D}^{1},{ }^{1}$ Jia-Ming Zhu ${ }^{(D)}{ }^{3}$ and Di Zhang ${ }^{2}$ \\ ${ }^{1}$ Institute of Sports Economics, Anhui University of Finance and Economics, Bengbu 233030, China \\ ${ }^{2}$ School of International Economics and Trade, Anhui University of Finance and Economics, Bengbu 233030, China \\ ${ }^{3}$ School of Statistics and Applied Mathematics, Anhui University of Finance and Economics, Bengbu 233030, China
}

Correspondence should be addressed to Zhi Gao; gicy0415@163.com

Received 11 July 2020; Revised 19 September 2020; Accepted 20 October 2020; Published 9 November 2020

Academic Editor: M. Javaid

Copyright ( $\odot 2020$ Li-Cai Zhu et al. This is an open access article distributed under the Creative Commons Attribution License, which permits unrestricted use, distribution, and reproduction in any medium, provided the original work is properly cited.

Large-scale sports stadiums are an important part of China's sports stadium system and an important material basis and prerequisite for China's basic public sports service system. This paper aims to establish the evaluation index system by exploring the utilization of large stadiums and gymnasiums under the background of sustainable development and to provide important reference for the construction and utilization of stadiums and gymnasiums in the future. Using literature methods, quantitative statistics, analytic hierarchy process (AHP), and other methods, focusing on sustainable use, this study develops a postgame utilization evaluation system for large stadiums, considering the design, construction, operation, and management of the stadium. This paper identifies 5 first-level indicators, 13 second-level indicators, and 38 third-level indicators, which mainly included five aspects of comprehensive performance, service level, environmental performance, economic performance, and venue maintenance. The AHP method was used to determine the index weight coefficient, thus forming a sustainable use evaluation index system for the large stadiums. Finally, taking Bengbu Sports Center in Anhui province as an example, this paper makes an empirical analysis.

\section{Introduction}

Large-scale sports stadiums, which are an important part of China's sports stadium system, are an important material basis and prerequisite for China's basic public sports service system. Since the 21st century, China has hosted a series of large-scale international sports events such as the Beijing Olympic Games, the Guangzhou Asian Games, and the World University Games. Moreover, various provinces and cities have hosted a series of large-scale national sports events such as the National Games and the Provincial Games. China has thus accumulated a large number of large-scale sports venues and stadiums. The sixth national sports census showed that as of the end of 2013, China had built 1,093 large stadiums [1]. With the Healthy China and the National Fitness Program becoming a national strategy, people's growing sports demand and the supply of public sports services have produced serious contradictions [2]. There are a series of problems behind the current situation of shortage and waste in the supply of stadiums and gymnasiums [3]. The "13th Five-Year Plan for Sports Development" indicated that it is necessary to actively promote the reform of the stadium management system and the innovation of operational mechanisms; it is also of great importance to improve the sports stadium operation evaluation system and to implement the integrated mode of venue design, construction, operation, and management in order to combine the demand for the event and a comprehensive postgame use of the stadiums in an organic way, strictly adhering to the scientific outlook on development [4]. Therefore, it is of great guiding significance and practical importance to construct a postgame utilization evaluation system for large stadiums, considering the design, construction, operation, and management of the stadium and focusing on sustainable utilization. Based on the comprehensive performance of stadiums and gymnasiums, service level, environmental performance, economic performance, and stadium maintenance, this paper constructs an 
evaluation system for the sustainable utilization of large-scale stadiums and gymnasiums after competition, including the whole life cycle of stadiums and gymnasiums design, construction, operation, and management, and constructs a fuzzy comprehensive evaluation model. The article focuses on whether the use of large stadiums and gymnasiums after the games is in line with the concept of sustainable development.

\section{Literature Review and Analysis}

2.1. Literature Review. Sports venues are an important part of public buildings and the basis for sports activities. They have the characteristics of large initial investment, high operating costs, and high resource consumption. In the context of the era of green development, stadiums should meet not only the development needs but also the requirements of resource conservation. The economic sustainability of stadiums was assessed also considering Emission Trading System, energy saving, and energy production [5]; in terms of site selection and distribution, Johnson indicated that in the early 20th century, stadiums were usually located in the city center, very close to the train station or in the public pedestrian area, because most people lived in and around the city center [6]. Fabris points out that sports stadiums and arenas have sustainability features [7]. Most studies on venue selection are focused on the city center or the city [8]. Compared with urban suburbs, city centers are more conducive to the development of the venue. Roger and Kemp believe that the extent of the development of public transportation systems around stadiums is an important factor in testing the pressure on stadium parking lots [9]. Therefore, it is a wise choice to locate stadiums in residential areas. The California Public Policy Research Institute indicated that there is an unequal distribution of public sports facilities. More than half of Californians agree that poor communities do not enjoy their fair share, and it is difficult to use well-preserved parks and sports facilities [10]. A study at the University of Southern California also found an imbalance in the Los Angeles park, where communities with low-income and colored populations find it more difficult to access public sports facilities than white and high-income communities [11]. Some scholars have suggested that the existing analysis model of individual responsibility and personal behavior choices for physical exercise should be transformed into social responsibility and an overall macro research model, focusing more on the role of environment and public policy in shaping lifestyle and behavioral patterns [12]. Norman et al. assessed the carbon emissions of the community from the three levels of community construction, construction operation, and transportation mode and concluded that the transportation mode has the greatest impact on carbon emissions [13]. Winkelman et al. reported that site selection and construction methods have a significant impact on the emissions of transportation infrastructure construction [14]. Burke and Shang indicated that whether large stadiums can be managed after the game is an important issue for event organizers in the initial stage of construction [15]. If the stadium is not used continuously after the game, the maintenance cost will be high. In the case of the London Olympics, it was decided that the main Olympic venues will be reduced in size and put into use after the games, and the temporary venues will be replanned for future urban construction [16]. In terms of venue operations, Santo analyzed a large amount of data in the field of stadium operation mode research, concluding that large stadiums have a facilitating effect on some local economies as well as some negative effects [17]. China's sports stadiums are mainly responsible for the training and competition of professional teams. They are not oriented to the masses and have a narrow business scope [18]. The usage rate of Chinese sports venues is also low. Many professional sports venues charge the public excessively, making few people choose professional sports venues as a place for fitness exercise. A significant number of stadiums are difficult to use, except for some big games [19]. Aljehani concludes that stadium scalability is impacted by urban form factors such as land uses density, accessibility, and connectivity. These factors impact the decision to scale down or up a stadium for better urban interactions [20]. Crompton et al. indicated that the current US stadium facilities mainly use public-private joint financing model-public private partnership-that is, both government and private investment in the construction of stadiums [21]. Rebeggiani drew on the financing model and tax policy of American stadiums and studied the investment operations of German stadiums [22]. Westerbeek et al. analyzed the success of the operation of a large-scale comprehensive sports stadium and the reasons for its success [23]. Based on a summary of these previous studies, the present study develops a sustainable postgame utilization evaluation system for large stadiums focusing on the relationship between venues, environment, and people.

2.2. Challenges and Gap Analysis. Some literatures promote the development of stadiums and gymnasiums from the perspectives of external environment, such as the site selection of stadiums and gymnasiums, the perfection degree of surrounding transportation system, and the distribution of public sports facilities. From the perspective of subjective factors, individual behavior patterns and personal responsibilities will also affect the sustainable use of venues. From the perspective of venue operation, investment and financing mode and government tax will also have a farreaching impact on venue development [24]. It can be concluded that most of the previous literature separated people, venues, and environment. The challenge of this paper is to integrate both subjective and objective factors into the evaluation system to make it complete and comprehensive.

\section{Value Basis and Principles of the Evaluation Index System for Sustainable Postgame Use of Large-Scale Stadiums}

The value bases of the evaluation system for sustainable utilization of large stadiums and gymnasiums are Revalue, Renew, Reuse, Reduce, and Recycle. Principles include comprehensiveness, scientificity, and operability.

3.1. Value Base. The concept of sustainable development can be summarized as follows: coordinating "the development of a natural-economic-social composite system without 
destroying the resources and environmental carrying capacity" [25]. The sustainable use of sports venues can be expressed as follows: the implementation of green development throughout the life cycle of a stadium, including site selection, planning, design, construction, use, postmatch operations, and construction materials. Sustainable development minimizes the damage to the natural and social environment and maximizes the efficient use of stadiums.

The value base of sustainable postmatch use of large-scale sports stadiums in China is mainly reflected in the $5 \mathrm{R}$ principles of sustainable development: Revalue, Renew, Reuse, Reduce, and Recycle. Revalue refers to "re-evaluation and rethinking." China is facing a contradiction between people's growing sports demand and the supply of public sports services. People's sports demand and the status quo of sports supply must be reconsidered. A balanced and sound public sports service system that meets people's diverse sports needs must be built. Renew refers to "revival and transformation." An improper postgame use and the backwardness of the operation management mechanism have led to a sharp increase in the loss and damage of the venue. It is necessary to strengthen the focus on the maintenance and renewal of stadiums. Reuse refers to "rerun and reutilization." The supply of sports venues presents a situation of shortage and waste, so it is necessary to reuse the stadiums after the competition, expand the open area and time, and improve the utilization rate of stadiums. Reduce refers to "reduction." During the construction and operation of sports venues, stadiums are designed with reasonable structure, and green materials are used to reduce the damage to nature. Recycle refers to "recycling," mainly in terms of the operation of sports venues, attempting to save energy, using recyclable resource materials, and improving the service life-span of stadiums.

Sustainable postmatch use of stadiums in China is based on the relationship between venues, environment, and people, and it can help solve the contradiction between the growing sports demand of the Chinese people and the supply of public sports services. In the whole life cycle of the venue, the principle of "improving the utilization rate of the stadium, improving the service life of the stadium, and reducing the impact on the environment" is the priority principle, and the $5 \mathrm{R}$ principles of sustainable development are implemented throughout the life cycle of the stadium. Based on the concept of sustainable development and considering the $5 \mathrm{R}$ principles, the life cycle diagram of large stadiums is constructed, as shown in Figure 1.

3.2. Principles. The process of postgame use of large-scale sports stadiums involves various levels of government and related functional departments, sports business organizations, the public, and other entities, and its impact is broad, diverse, and complex. Therefore, in establishing a postmatch evaluation system of large-scale sports stadiums, it is necessary to consider not only the current situation of the construction and operation of various sports venues in China but also the economic, social, and natural impacts of stadiums. The goal of the system is to achieve a people-oriented, harmonious coexistence between man and nature and sustainable development. The system strives to reflect not only its application adaptability but also the guiding significance of policy, based on the status quo as well as future directions.

3.2.1. Comprehensiveness. The postgame use of large-scale sports stadiums involves multiagent, far-reaching, multiobjective system engineering, not only related to the postgame operation stage of the stadium but also affected by the construction stage and the stage of the use for the event, and it covers the entire life cycle of large stadiums. At the same time, due to the interaction of social, economic, and natural factors, the evaluation system needs to be completed by venue management department, government departments, and the public. In the process of establishing such an evaluation system, it is necessary to emphasize the theme of sustainable use of largescale sports stadiums based on inheriting the social service and economic performance of general venue evaluation and to closely link society, people, and nature in order to achieve the goal of coordinated development of these three aspects. To make the whole evaluation system more systematic and comprehensive, it is necessary that the system reflects not only the current operational status of the stadium but also its development potential, sustainable development, and the attributes of resource optimization.

3.2.2. Scientific Nature. The scientific nature of the indicator system is the basis for ensuring accurate and reasonable evaluation results. First, the selected indicators should reflect the essential characteristics of the postgame use of sports stadiums, the status quo of stadium supply and demand, and the theme of sustainable use. Second, there are many factors influencing the use of gymnasiums after holding sports matches, and there is a certain correlation between them. It is necessary to ensure the independence of each index and to avoid an overlap with attributes and connotations. Finally, the indicator system should focus on the goal of sustainable use and comprehensively reflect the performance of the postgame use of sports stadiums, including both positive and negative performance evaluation, and important indicators cannot be omitted.

3.2.3. Operability. The selection of indicators should consider theoretical rationality and the actual situation of the postgame operation of gymnasiums in China to ensure that the indicators can be collected more accurately. At the same time, it is necessary to comprehensively use absolute and relative value indicators, quantitative and qualitative indicators, and short-term and long-term indicators to embody specific evaluation indicators and make the evaluation operable.

\section{Construction of Sustainable Postmatch Utilization Evaluation Index System for Large-Scale Stadiums}

Starting from China's actual national conditions, this study designs a preliminary indicator system based on the theme of sustainable use, drawing on the rich research results of its predecessors, and then constructing a comprehensive indicator system of five first-level indicators, including 


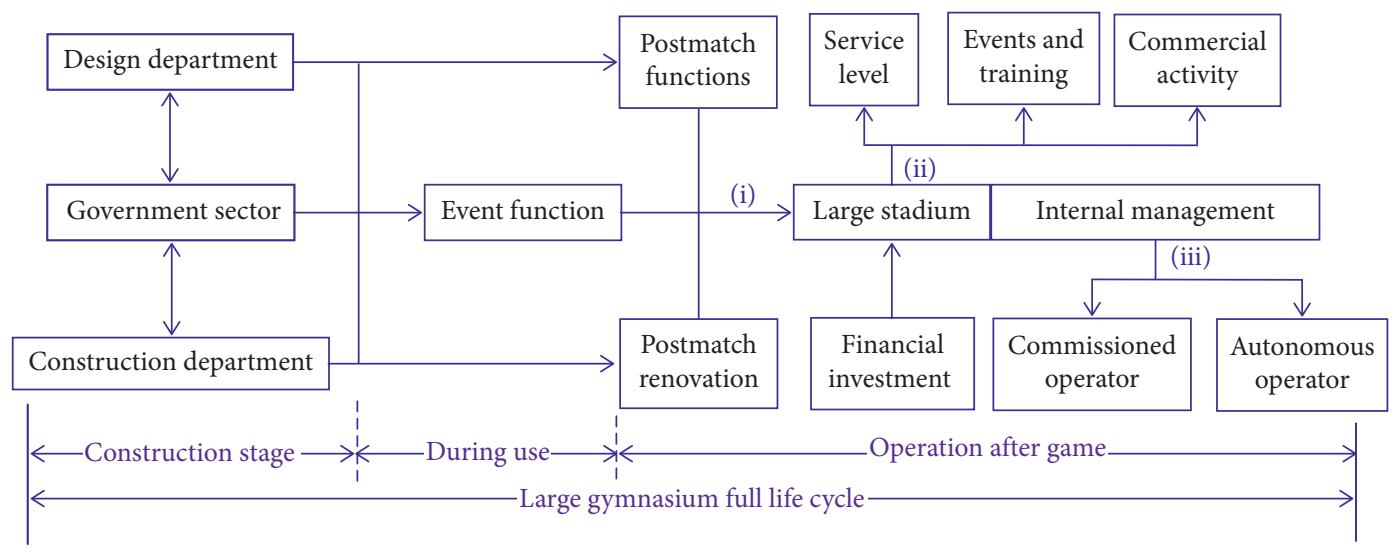

(i) The postgame functional transformation;

(ii) After the stadium is open to use;

(iii) The stadium operation management model.

Figure 1: Full life cycle diagram of a large stadium.

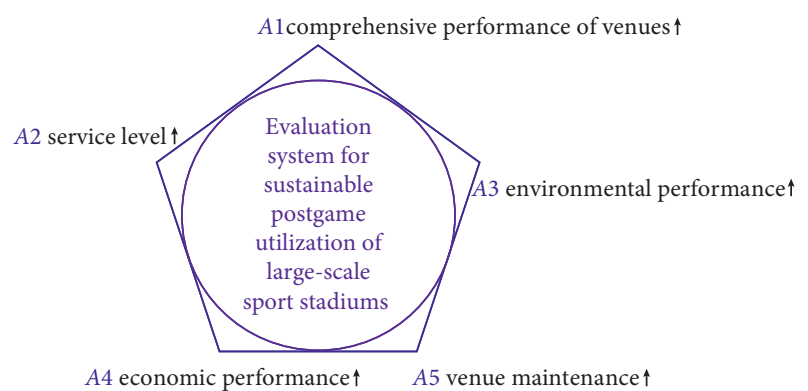

Figure 2: Evaluation index system for the sustainable use of large stadiums.

comprehensive performance, service level, environmental performance, and economic performance of the venue, through expert interviews and questionnaires (Figure 2).

\subsection{Comprehensive Performance of the Venue (A1). A sta-} dium is an arena for sports competitions, sports training, and public fitness needs. The comprehensive performance of the stadium is the key planning content before stadium construction, and it is the basis for the stadium to be fully utilized after a competition. Infrastructure is the material basis for the comprehensive performance of the venue, which can be measured in terms of facility scale, supporting facilities, safety facilities, and sanitation. Social environment is an external guarantee for the comprehensive performance of the venue, which includes traffic environment and population density. The management system is the core of the comprehensive performance of the venue, mainly reflected in the operation management mechanism, organizational structure, and talent support.

4.2. Service Level (A2). The service level of the stadium is the embodiment of the core value of the stadium, which can be evaluated from the aspects of utilization level and activity bearing.
Utilization level mainly reflects the utilization rate and openness of stadiums in sports events, training, and other activities. Therefore, it includes open area, opening hours, and number of receptions. Open area is measured by the proportion of the actual use of the stadium to the building area of the stadium. Open time conditions are measured using the weekly average opening hours of the stadium for service levels. The number of receptions is measured by the number of people in the stadium.

Activity bearing capacity mainly reflects the ability of sports venues to host large-scale events such as sports events, exhibitions, and cultural performances. It can be measured from the following four categories: sports events, sports training, public fitness activities, and commercial activities.

4.3. Environmental Performance (A3). Environmental performance is used to measure the quality of the natural environment of the stadium and the pollution and damage to the natural environment, including energy consumption, environmental load, environmental pollution, and indoor environmental quality. The energy consumption of stadiums mainly refers to the electricity and water consumed in the daily operation of stadiums. Environmental load indicates the influence of the building's architectural body on the natural environment around the stadium, which mainly includes wind environment and groundwater system. Environmental pollution mainly refers to air pollution, water pollution, and solid waste generated by the daily operation of stadiums. Indoor environmental quality is a collection of various environmental factors in the interior of the stadium when people perform sports activities, including sound, heat, air, and light.

4.4. Economic Performance (A4). Economic performance is the most basic evaluation content for the postmatch use of large-scale sports stadiums. It refers to the economic benefits of sports and expenditures of various public or business activities. It can be measured by economic income and expenditure. The 
economic income of stadiums and gymnasiums mainly comes from fiscal appropriation, fiscal subsidy, and commercial income, while the economic expenditure includes basic and project expenditure.

4.5. Venue Maintenance (A5). Venue maintenance is the material basis for the sustainable use of stadiums. It is measured by two types of indicators: stadium maintenance funds and venues' fixed assets loss. The sixth national sports census showed that, as of the end of 2013, $90 \%$ of large stadiums in China adopted an independent business model. The short-term behavior of venues brought by the independent business model caused the loss and damage of some venues to increase sharply, and the maintenance costs also rose sharply. As a result, the fixed assets loss of a venue is a serious issue, so the use of depreciation and the proportion of new fixed assets is measured. In the management of public sports venues, China generally adopts the state financial allocation method to address the maintenance of houses, venues, and large-scale equipment in public sports venues [26]. However, the significant operating costs will inevitably result in a financial burden on relevant government departments. Therefore, it is necessary to operate stadiums through multiple channels [27]. Venue maintenance funds should be measured by financial maintenance funds input and other maintenance funds.

\section{Weight Determinations of Sustainable Postmatch Use Evaluation Indicators of Large-Scale Stadiums}

The Analytic Hierarchy Process (AHP) was introduced by T. L. Saaty, a professor at the University of Pittsburgh in the mid-1970s. Its basic idea is to decompose a complex problem into various components and then group these factors into dominance relationships to form an ordered hierarchical structure. The relative importance of the factors in the hierarchy is determined by means of a pairwise comparison, and then the judgment of the person is integrated to determine the overall order of the relative importance of the factors of the decision. AHP has made it convenient for decision makers to solve decision-making problems that are difficult to quantify, so its application covers almost any scientific field. In this study, eight field management experts were invited to create two points for the evaluation indicators. The steps for determining the weight of the first-level indicators are as follows:

(1) Ask the eight experts to refer to the judgment matrix scale definition table (Table 1) to assign scores to the five first-level indicators and then statistically organize the assigned scores to obtain the judgment matrix A (Table 2). The scores of each indicator in the judgment matrix are obtained by the average of the scores assigned by the eight experts.
(2) The largest eigenvalue $\lambda_{\max }$ of the judgment matrix $A$ and its corresponding normalized eigendirection are calculated as $W=\left[W_{1}, W_{2}, W_{3}, W_{4}, W_{5}\right]^{T}$, and eigenvector $W=\left[W_{1}, W_{2}, W_{3}, W_{4}, W_{5}\right]^{T}$ is the weight vector of the evaluation unit, calculated by the geometric average method (square root method) $\lambda_{\max }$ with $W$

(i) From the formula $M_{i}=\prod_{i=1}^{n} b_{i j}(i=1,2, \ldots, n)$, we can get

$$
\begin{aligned}
& M_{1}=1 \times \frac{13}{24} \times \frac{7}{12} \times \frac{5}{4} \times \frac{5}{4}=\frac{39}{79}=0.49371 \\
& M_{2}=\frac{5}{2} \times 1 \times \frac{3}{2} \times \frac{5}{2} \times \frac{3}{2}=\frac{225}{16}=14.0625 \\
& M_{3}=\frac{9}{4} \times \frac{3}{4} \times 1 \times \frac{9}{4} \times \frac{7}{8}=\frac{299}{90}=3.32227 \\
& M_{4}=\frac{7}{8} \times \frac{5}{12} \times \frac{11}{24} \times 1 \times \frac{11}{24}=\frac{1}{13}=0.07659, \\
& M_{5}=\frac{9}{4} \times \frac{7}{8} \times \frac{5}{4} \times \frac{9}{4} \times 1=\frac{299}{54}=5.53711 .
\end{aligned}
$$

(ii) Compute the $n$th root of $M_{i}, \bar{W}_{i}=\sqrt[n]{M_{i}}$ :

$$
\begin{aligned}
& \bar{W}_{1}=\sqrt[5]{M_{1}}=\sqrt[5]{0.49371}=0.86835 \\
& \bar{W}_{2}=\sqrt[5]{M_{2}}=\sqrt[5]{14.0625}=1.69673 \\
& \bar{W}_{3}=\sqrt[5]{M_{3}}=\sqrt[5]{3.32227}=1.27414 \\
& \bar{W}_{4}=\sqrt[5]{M_{4}}=\sqrt[5]{0.07659}=0.59818 \\
& \bar{W}_{5}=\sqrt[5]{M_{5}}=\sqrt[5]{5.53711}=1.40817
\end{aligned}
$$

(iii) Use the formula $W_{i}=\bar{W}_{i} / \sum_{i=1}^{n} \bar{W}_{i}$ to normalize the vector $\bar{W}=\left[\bar{W}_{1}, \bar{W}_{2}, \bar{W}_{3}, \bar{W}_{4}, \bar{W}_{5}\right]^{T}$, calculate $W_{i}$ separately, and get the eigenvector $W=\left[W_{1}, W_{2}, W_{3}, W_{4}, W_{5}\right]^{T}$ :

$$
\begin{aligned}
& W_{1}=\frac{0.86835}{5.84285}=0.14862 \\
& W_{2}=\frac{1.69673}{5.84285}=0.29039 \\
& W_{3}=\frac{1.27141}{5.84285}=0.2176 \\
& W_{4}=\frac{0.59818}{5.84285}=0.10238 \\
& W_{5}=\frac{1.40817}{5.84285}=0.24101
\end{aligned}
$$


So, the feature vector is $W=[0.14862,0.29039$, $0.2176,0.10238,0.24102]^{T}$.

(iv) The largest eigenvalue $\lambda_{\max }$ of the judgment matrix $A$ is calculated by the formula, $(A W)_{i}$ is the factor of the vector $A W$ :

$$
\begin{aligned}
& (A W)_{1}=1 \times 0.14862+\frac{13}{24} \times 0.29039+\frac{7}{12} \times 0.2176 \\
& +\frac{5}{4} \times 0.10238+\frac{5}{4} \times 0.24101=0.86208 \\
& (A W)_{2}=\frac{5}{2} \times 0.14862+1 \times 0.29039+\frac{3}{2} \times 0.2176 \\
& +\frac{5}{2} \times 0.10238+\frac{3}{2} \times 0.24101=1.6058, \\
& (A W)_{3}=\frac{9}{4} \times 0.14862+\frac{3}{4} \times 0.29039+1 \times 0.2176 \\
& +\frac{9}{4} \times 0.10238+\frac{7}{8} \times 0.24101=1.21102 \\
& (A W)_{4}=\frac{7}{8} \times 0.14862+\frac{5}{12} \times 0.29039+\frac{11}{24} \times 0.2176 \\
& +1 \times 0.10238+\frac{11}{24} \times 0.24101=0.56361, \\
& (A W)_{5}=\frac{9}{4} \times 0.14862+\frac{7}{8} \times 0.29039+\frac{5}{4} \times 0.2176 \\
& +\frac{9}{4} \times 0.10238+1 \times 0.24101=1.33185 \\
& \lambda_{\max }=\sum_{i=1}^{n} \frac{(A W)_{i}}{5 W_{i}}=\frac{(A W)_{1}}{5 W_{1}}+\frac{(A W)_{2}}{5 W_{2}}+\frac{(A W)_{3}}{5 W_{3}} \\
& +\frac{(A W)_{4}}{5 W_{4}}+\frac{(A W)_{5}}{5 W_{5}} \\
& =\frac{0.86208}{5 \times 0.14862}+\frac{1.6058}{5 \times 0.29039}+\frac{1.21102}{5 \times 0.2176} \\
& +\frac{0.56361}{5 \times 0.10238}+\frac{1.33285}{5 \times 0.24101}=5.28541 .
\end{aligned}
$$

(3) The consistency test of the judgment matrix $A$ is carried out by the formula C.R. = C.I./R.I.:

Consistency index C.I. $=\left(\lambda_{\max }-n\right) /(n-1)=(5.28541-$ $5) /(5-1)=0.07135$, Average random consistency index R.I. $=1.12$.

C.R. $=($ C.I. $/$ R.I. $)=(0.07135 / 1.12)=0.06371<0.10 . \quad$ It can be considered that the judgment matrix $A$ passes the consistency test.
Therefore, the weights of $A_{1}, A_{2}, A_{3}, A_{4}, A_{5}$ are, respectively, $0.14862,0.29039,0.2176,0.10238$, and 0.24101 .

Similarly, according to the above five steps, the weights of second and third level indicators at a single level can be calculated, and finally, the combined weights at each level can be calculated according to the weights of the indicators at each single level (Table 3 ).

\section{Research on Fuzzy Comprehensive Evaluation Model for Sustainable Postmatch Use of Large-Scale Sports Venues}

Large-scale sports venues in China are not only used for large-scale events but are also included in the Chinese sports stadium system for postgame utilization and to continue to serve the public. Large-scale sports stadiums serve the general public in competition, training, fitness, and watching, so the design and construction of sports venues, postgame operating modes, and other factors are fundamental factors for the sustainable postgame use of large stadiums. In the sustainable postgame use evaluation index system of large-scale sports stadiums, there are both quantitative and qualitative indicators. Quantitative indicators can be obtained by collecting relevant data, while qualitative indicators cannot be accurately measured, as they reflect the intuitive feelings of the service objects. Therefore, the membership degree of quantitative indicators can be determined by collecting relevant data, and the membership degree of qualitative indicators can be determined by the multiple levels of fuzzy comprehensive evaluation method.

\subsection{Indicator Evaluation Corpus}

6.1.1. Quantitative Indicator Evaluation Corpus. Among the first-level indicators of the sustainable postgame use evaluation index system for large-scale sports stadiums, only the $A 2$ service level can be determined by collecting relevant data. The evaluation corpus adopts the "Comprehensive Evaluation System for Large-Scale Sports Facilities Operation Management" promulgated by the State Sports General Administration of China (Table 4).

6.1.2. Qualitative Indicator Evaluation Corpus. The qualitative evaluation index of the evaluation index system for the sustainable use of large stadiums is \{excellent, good, pass, poor, very poor $\}$; the corresponding evaluation value set $V$ is $\{1.0,0.8,0.6,0.4,0.2\}$.

6.2. Evaluation Object and Research Object Selection. A case study was conducted using the Bengbu Sports Center in Anhui province, China. The construction of the stadium was completed in 2018, and it hosted the 14th Anhui Provincial Games in October of the same year. It has been a year since the hosting of this large-scale event. Therefore, an evaluation of the continuous use of Bengbu 
TABLE 1: Judgment matrix scale definition table.

$\begin{aligned} & \text { Scale } \\ & 1\end{aligned}$
3
5
9
$\begin{aligned} & \text { Indicates that } A_{i} \text { is of equal importance to } A_{j} \\ & \text { Indicates that } A_{i} \text { is slightly more important than } A_{j}\end{aligned}$
Indicates that the indicator $A_{i}$ is significantly more important than the latter $A_{j}$
Indicates that the indicator $A_{i}$ is extremely important compared to the indicator $A_{j}$
Represent the intermediate values of the above adjacent judgment
If the ratio of the importance of indicators $A_{i}$ to indicators $A_{j}$ is $a_{i j}$, then the ratio of the importance of indicators to indicators is
$a_{j i}=1 / a_{i j}$

TABle 2: Level 1 indicator judgment matrix $A$.

\begin{tabular}{cccccc}
\hline$A$ & $A_{1}$ & $A_{2}$ & $A_{3}$ & $A_{4}$ & $A_{5}$ \\
\hline$A_{1}$ & 1 & $13 / 24$ & $7 / 12$ & $5 / 4$ & $5 / 4$ \\
$A_{2}$ & $5 / 2$ & 1 & $3 / 2$ & $5 / 2$ & $3 / 2$ \\
$A_{3}$ & $9 / 4$ & $3 / 4$ & 1 & $9 / 4$ & $7 / 8$ \\
$A_{4}$ & $7 / 8$ & $5 / 12$ & $11 / 24$ & 1 & $11 / 24$ \\
$A_{5}$ & $9 / 4$ & $7 / 8$ & $5 / 4$ & $9 / 4$ & 1 \\
\hline
\end{tabular}

Sports Center can play a very important reference role. The subjective evaluation of qualitative indicators was carried out through on-site stratified random distribution and questionnaire recovery. Sports trainers, sports staff, venue managers, audiences, general fitness people, and other people were selected for the questionnaire survey. A total of 200 questionnaires were distributed, and 192 copies were collected, of which, 185 were valid questionnaires. Respondents' basic information is shown in Table 5.

\subsection{Indicator Score Calculation}

6.3.1. Quantitative Index Score Calculation. By examining the "Bengbu Sports Center 2018 Opening Work Plan," the "2018 City Sports Bureau Government Information Disclosure Annual Work Report," and other related documents, the membership degree of the three-level evaluation index of the stadium's service level was determined, and it was combined with the weights of the evaluation indicators at each level, calculating the scores of the indicators at each level.

6.3.2. Calculation of Qualitative Indicator Score. Due to the professionalism of index evaluation, some indicators are evaluated by specific survey targets in the indicator system. Therefore, the $A 3$ environmental performance evaluation index was selected as an example for analysis. This index was investigated in the 185 valid questionnaires.

(i) Determining the degree of membership of the three levels of environmental performance indicators

The 185 valid questionnaires were counted according to the grades of qualitative indicators and normalized, and the proportion of people selected for each evaluation level was obtained, which is the membership degree of environmental performance of the three-level indicators (Table 6).

(ii) Constructing the fuzzy membership relation matrix of the environmental performance of the three-level index:

$$
\begin{aligned}
& R 31=\left[\begin{array}{lllll}
0.141 & 0.173 & 0.373 & 0.238 & 0.076 \\
0.092 & 0.249 & 0.427 & 0.173 & 0.065
\end{array}\right], \\
& R 32=\left[\begin{array}{lllll}
0.103 & 0.205 & 0.265 & 0.205 & 0.222 \\
0.189 & 0.184 & 0.405 & 0.141 & 0.081
\end{array}\right], \\
& R 33=\left[\begin{array}{lllll}
0.157 & 0.222 & 0.319 & 0.200 & 0.103 \\
0.135 & 0.173 & 0.378 & 0.157 & 0.157 \\
0.146 & 0.222 & 0.254 & 0.184 & 0.195
\end{array}\right], \\
& R 34=\left[\begin{array}{lllll}
0.168 & 0.265 & 0.222 & 0.195 & 0.151 \\
0.157 & 0.227 & 0.265 & 0.168 & 0.184 \\
0.151 & 0.211 & 0.330 & 0.195 & 0.114 \\
0.168 & 0.157 & 0.389 & 0.184 & 0.103
\end{array}\right] .
\end{aligned}
$$

(iii) Establishing the three-level fuzzy comprehensive evaluation model of environmental performance: 
TABLE 3: Evaluation index system for sustainable postgame utilization of large-scale sports stadiums.

\begin{tabular}{|c|c|c|c|c|c|}
\hline \multicolumn{2}{|l|}{ First class indicator $A$} & \multicolumn{2}{|l|}{ Second class indicator $B$} & \multicolumn{2}{|l|}{ Third class indicator $C$} \\
\hline Index & Weight & Index & Weight & Index & Weight \\
\hline \multirow{9}{*}{$\begin{array}{l}\text { A1 comprehensive performance } \\
\text { of venues }\end{array}$} & \multirow{9}{*}{0.14862} & \multirow{4}{*}{$B 11$ infrastructure } & \multirow{4}{*}{0.05945} & \multirow{9}{*}{$\begin{array}{c}\text { C111 facilities size } \\
\text { C112 supporting facilities } \\
\text { C113 safety facilities } \\
\text { C114 health facility } \\
\text { C121 traffic environment } \\
\text { C122 density of population } \\
\text { C131 the mechanism of operation and } \\
\text { management } \\
\text { C132 organization structure } \\
\text { C133 talent support }\end{array}$} & 0.01783 \\
\hline & & & & & 0.01783 \\
\hline & & & & & 0.01189 \\
\hline & & & & & 0.01189 \\
\hline & & & & & 0.02229 \\
\hline & & B12 social environment & 0.04459 & & 0.02229 \\
\hline & & & & & 0.01783 \\
\hline & & $B 13$ management system & 0.04459 & & 0.01338 \\
\hline & & & & & 0.01338 \\
\hline \multirow{7}{*}{ A2 service level } & \multirow{7}{*}{0.29039} & \multirow{4}{*}{ B21 utilization } & \multirow{4}{*}{0.14520} & C211 open area & 0.04356 \\
\hline & & & & C212 opening hours & 0.04356 \\
\hline & & & & $C 213$ the number of reception & 0.05808 \\
\hline & & & & C221 sports event & 0.04356 \\
\hline & & \multirow{3}{*}{$B 22$ organized activities } & \multirow{3}{*}{0.14520} & C222 exercise training & 0.04356 \\
\hline & & & & C223 public fitness program & 0.03630 \\
\hline & & & & C224 commercial activity & 0.02178 \\
\hline \multirow{11}{*}{$A 3$ environmental performance } & \multirow{11}{*}{0.2176} & \multirow{2}{*}{ B31 energy consumption } & \multirow{2}{*}{0.04352} & C311 electricity & 0.02176 \\
\hline & & & & C312 water & 0.02176 \\
\hline & & \multirow{3}{*}{ B32 environmental load } & \multirow{2}{*}{0.04352} & C321 wind environment & 0.02176 \\
\hline & & & & C322 underground water & 0.02176 \\
\hline & & & \multirow{3}{*}{0.06528} & C331 atmosphere & 0.01632 \\
\hline & & \multirow[t]{2}{*}{ B33 environmental pollution } & & C332 water pollution & 0.02285 \\
\hline & & & & C333 solid waste & 0.02611 \\
\hline & & \multirow{4}{*}{$\begin{array}{c}\text { B34 indoor environmental } \\
\text { quality }\end{array}$} & \multirow{4}{*}{0.06528} & C341 sound & 0.01278 \\
\hline & & & & C342 temperature & 0.01331 \\
\hline & & & & C343 air & 0.01472 \\
\hline & & & & C344 light & 0.01464 \\
\hline \multirow{5}{*}{ A4 economic performance } & \multirow{5}{*}{0.10238} & \multirow{3}{*}{ B41 economic income } & \multirow{3}{*}{0.05119} & C411 revenue from appropriation & 0.01024 \\
\hline & & & & C412 revenue from fiscal subsidies & 0.01536 \\
\hline & & & & C413 business revenue & 0.02559 \\
\hline & & $B 42$ economic expenditure & 0.05119 & C421 basic expenditure & 0.02559 \\
\hline & & B42 economic expenaiture & 0.05119 & C422 project expenditure & 0.02559 \\
\hline & & B51 expenditure for venue & 0.12051 & C511 fiscal investment & 0.04820 \\
\hline$A 5$ venue maintenance & 0.24101 & क्र & & C512 other maintenance expenses & 0.07230 \\
\hline & & B52 loss of stadium fixed assets & 0.12051 & $\begin{array}{l}\text { C521 fixed assets depreciation and new } \\
\text { proportion }\end{array}$ & 0.12051 \\
\hline
\end{tabular}

TABLE 4: Service level indicator evaluation.

\begin{tabular}{lccccc}
\hline Index & Excellent/1.0 & Good/0.8 & Pass $/ 0.6$ & Poor/0.4 & Very poor/0.2 \\
\hline C211 & $80 \%-100 \%$ & $70 \%-79 \%$ & $60 \%-69 \%$ & $50 \%-59 \%$ & $40 \%-49 \%$ \\
C212 & 50 hours per week or above & $46-50 \mathrm{~h}$ & $41-45 \mathrm{~h}$ & $36-40 \mathrm{~h}$ & Less than $35 \mathrm{~h}$ \\
C213 & Over 100,000 times & 80,000 to 90,000 times & 60,000 to 70,000 times & 40,000 to 50,000 times & Less than 40,000 times \\
C221 & More than 10 times & 8 to 9 times & 6 to 7 times & 3 to 5 times & Less than 3 times \\
C222 & More than 10 times & 8 to 9 times & 6 to 7 times & 3 to 5 times & 1 to 2 times \\
C223 & More than 10 times & 8 to 9 times & 6 to 7 times & 3 to 5 times & 1 to 2 times \\
C224 & More than 10 times & 8 to 9 times & 6 to 7 times & 3 to 5 times & 1 to 2 times \\
\hline
\end{tabular}

TABLE 5: Basic information of the survey object.

\begin{tabular}{lccccc}
\hline Property & Proportion (\%) & Age & Proportion (\%) & Schooling & Proportion (\%) \\
\hline Sports trainers & 14.05 & Under 18 & 11.35 & Below senior high school & Senior high school \\
Sports staff & 23.24 & $18-30$ & 28.11 & Technical secondary school & B. \\
Venue managers & 8.64 & $30-45$ & 30.27 & Bachelor & 33.51 \\
Audiences & 22.16 & $45-60$ & 17.3 & Graduate or above & 35.68 \\
General fitness people & 31.91 & At least 60 & 12.97 & 7.02 \\
\hline
\end{tabular}


TABLE 6: Degree of subordination of environmental performance of large stadiums.

\begin{tabular}{|c|c|c|c|c|c|c|c|c|c|c|}
\hline \multirow{3}{*}{ Index } & \multicolumn{10}{|c|}{ Evaluation } \\
\hline & \multicolumn{2}{|c|}{ Excellent } & \multicolumn{2}{|c|}{ Good } & \multicolumn{2}{|c|}{ Pass } & \multicolumn{2}{|c|}{ Poor } & \multicolumn{2}{|c|}{ Very poor } \\
\hline & Number & Proportion & Number & Proportion & Number & Proportion & Number & Proportion & Number & Proportion \\
\hline C311 & 26 & 0.141 & 32 & 0.173 & 69 & 0.373 & 44 & 0.238 & 14 & 0.076 \\
\hline C312 & 17 & 0.092 & 46 & 0.249 & 79 & 0.427 & 32 & 0.173 & 12 & 0.065 \\
\hline C321 & 19 & 0.103 & 38 & 0.205 & 49 & 0.265 & 38 & 0.205 & 41 & 0.222 \\
\hline C322 & 35 & 0.189 & 34 & 0.184 & 75 & 0.405 & 26 & 0.141 & 15 & 0.081 \\
\hline C331 & 29 & 0.157 & 41 & 0.222 & 59 & 0.319 & 37 & 0.200 & 19 & 0.103 \\
\hline C332 & 25 & 0.135 & 32 & 0.173 & 70 & 0.378 & 29 & 0.157 & 29 & 0.157 \\
\hline C333 & 27 & 0.146 & 41 & 0.222 & 47 & 0.254 & 34 & 0.184 & 36 & 0.195 \\
\hline C341 & 31 & 0.168 & 49 & 0.265 & 41 & 0.222 & 36 & 0.195 & 28 & 0.151 \\
\hline C342 & 29 & 0.157 & 42 & 0.227 & 49 & 0.265 & 31 & 0.168 & 34 & 0.184 \\
\hline C343 & 28 & 0.151 & 39 & 0.211 & 61 & 0.330 & 36 & 0.195 & 21 & 0.114 \\
\hline C344 & 31 & 0.168 & 29 & 0.157 & 72 & 0.389 & 34 & 0.184 & 19 & 0.103 \\
\hline
\end{tabular}

$$
\begin{aligned}
& B 31=\left(\begin{array}{ll}
0.02176 & 0.02176
\end{array}\right) \times\left[\begin{array}{lllll}
0.141 & 0.173 & 0.373 & 0.238 & 0.076 \\
0.092 & 0.249 & 0.427 & 0.173 & 0.065
\end{array}\right]=\left(\begin{array}{lllll}
0.00507 & 0.00918 & 0.01741 & 0.00894 & 0.00307
\end{array}\right)
\end{aligned}
$$

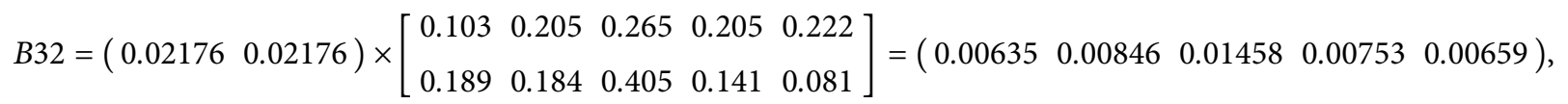

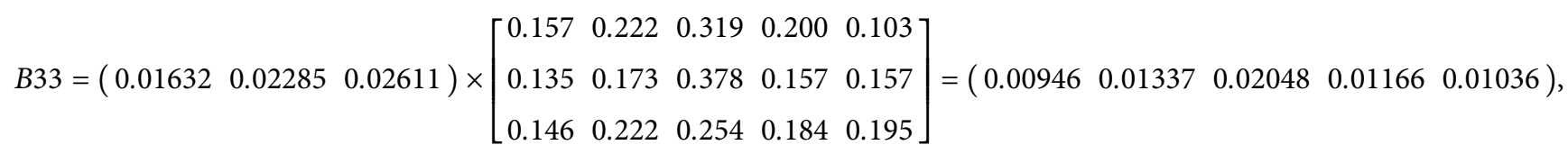

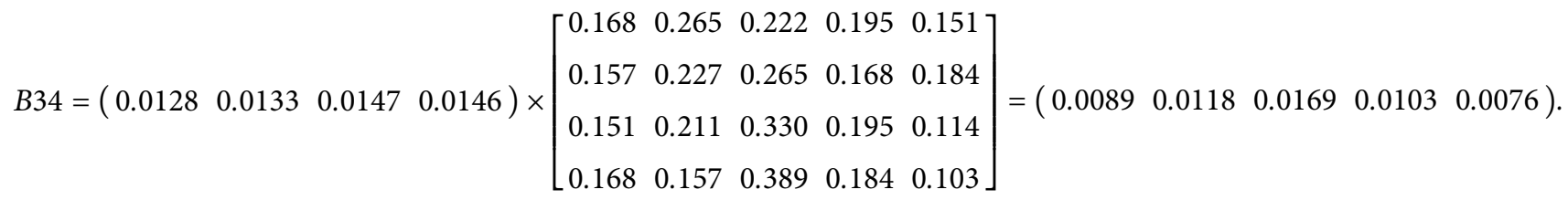

(iv) Establishing a fuzzy comprehensive evaluation model of environmental performance

Based on the fuzzy comprehensive evaluation results of the three-level indicators of environmental performance, the fuzzy membership relation matrix of two-level indexes of environmental performance was constructed; the fuzzy comprehensive evaluation model of two-level indexes of environmental performance was established by combining the weight vector of two-level indexes of environmental performance.

$$
\begin{aligned}
A 3 & =\left(\begin{array}{llll}
0.04352 & 0.04352 & 0.06528 & 0.06528
\end{array}\right) \times\left[\begin{array}{lllll}
0.00507008 & 0.00918272 & 0.01740800 & 0.00894336 & 0.00306816 \\
0.00635392 & 0.00846464 & 0.01457920 & 0.00752896 & 0.00659328 \\
0.00945905 & 0.01337251 & 0.02047532 & 0.01165569 & 0.01035986 \\
0.00891895 & 0.01181247 & 0.01691687 & 0.01029234 & 0.00756484
\end{array}\right] \\
& =\left(\begin{array}{lllll}
0.001696888 & 0.002412089 & 0.003833045 & 0.002149643 & 0.001590589
\end{array}\right) .
\end{aligned}
$$


TABLE 7: Evaluation scores of sustainable postmatch use of Bengbu Sports Center.

\begin{tabular}{|c|c|c|c|c|c|}
\hline \multicolumn{2}{|l|}{ First class indicator $A$} & \multicolumn{2}{|l|}{ Second class indicator $B$} & \multicolumn{2}{|l|}{ Third class indicator $C$} \\
\hline Index & Score & Index & Score & Index & Score \\
\hline \multirow{9}{*}{$\begin{array}{l}\text { A1 comprehensive } \\
\text { performance } \\
\text { of venues }\end{array}$} & \multirow{9}{*}{0.6609} & \multirow{4}{*}{$B 11$ infrastructure } & \multirow{4}{*}{0.6976} & \multirow{9}{*}{$\begin{array}{c}\text { C111 facilities size } \\
\text { C112 supporting facilities } \\
\text { C113 safety facilities } \\
\text { C114 health facility } \\
\text { C121 traffic environment } \\
\text { C122 density of population } \\
\text { C131 the mechanism of operation and } \\
\text { management } \\
\text { C132 organization structure } \\
\text { C133 talent support }\end{array}$} & 0.6973 \\
\hline & & & & & 0.6962 \\
\hline & & & & & 0.6811 \\
\hline & & & & & 0.7168 \\
\hline & & $R 12$ cocinl onvironment & 06611 & & 0.6627 \\
\hline & & B12 social environment & 0.6611 & & 0.6595 \\
\hline & & & & & 0.6001 \\
\hline & & $B 13$ management system & 0.5958 & & 0.5978 \\
\hline & & & & & 0.5881 \\
\hline \multirow{7}{*}{$A 2$ service level } & \multirow{7}{*}{0.725} & \multirow{7}{*}{$B 22$ organized activities } & \multirow{4}{*}{0.78} & C211 open area & 0.8 \\
\hline & & & & C212 opening hours & 1.0 \\
\hline & & & & $C 213$ the number of reception & 0.6 \\
\hline & & & & C221 sports event & 0.8 \\
\hline & & & 067 & C222 exercise training & 1.0 \\
\hline & & & 0.67 & C223 public fitness program & 0.4 \\
\hline & & & & C224 commercial activity & 0.2 \\
\hline \multirow{11}{*}{$\begin{array}{l}\text { A3 environmental } \\
\text { performance }\end{array}$} & \multirow{11}{*}{0.6081} & \multirow{2}{*}{ B31 energy consumption } & \multirow{2}{*}{0.6194} & C311 electricity & 0.6136 \\
\hline & & & & C312 water & 0.6296 \\
\hline & & \multirow{3}{*}{ B32 environmental load } & \multirow{2}{*}{0.6021} & C321 wind environment & 0.5524 \\
\hline & & & & C322 underground water & 0.6518 \\
\hline & & & \multirow{4}{*}{0.5997} & C331 atmosphere & 0.6266 \\
\hline & & \multirow[t]{3}{*}{ B33 environmental pollution } & & C332 water pollution & 0.5944 \\
\hline & & & & C333 solid waste & 0.5886 \\
\hline & & & & C341 sound & 0.6214 \\
\hline & & \multirow{3}{*}{ B34 indoor environmental quality } & \multirow{3}{*}{0.6152} & C342 temperature & 0.6016 \\
\hline & & & & C343 air & 0.6186 \\
\hline & & & & C344 light & 0.6212 \\
\hline \multirow{5}{*}{ A4 economic performance } & \multirow{5}{*}{0.5681} & \multirow{3}{*}{ B41 economic income } & \multirow{3}{*}{0.5244} & C411 revenue from appropriation & 0.6136 \\
\hline & & & & C412 revenue from fiscal subsidies & 0.6949 \\
\hline & & & & C413 business revenue & 0.3864 \\
\hline & & \multirow{2}{*}{ B42 economic expenditure } & \multirow{2}{*}{0.6118} & C421 basic expenditure & 0.6102 \\
\hline & & & & C422 project expenditure & 0.6136 \\
\hline & & B51 expenditure for venue & 0.6583 & C511 fiscal investment & 0.6441 \\
\hline A5 venue maintenance & 0.6902 & maintenance & & C512 other maintenance expenses & 0.6678 \\
\hline & & B52 loss of stadium fixed assets & 0.7220 & $\begin{array}{l}\text { C521 fixed assets depreciation and new } \\
\text { proportion }\end{array}$ & 0.7220 \\
\hline
\end{tabular}

Total value: 0.6656

(v) Calculating the fuzzy comprehensive evaluation results of environmental performance $A 3$ was normalized: 
The environmental performance evaluation score is

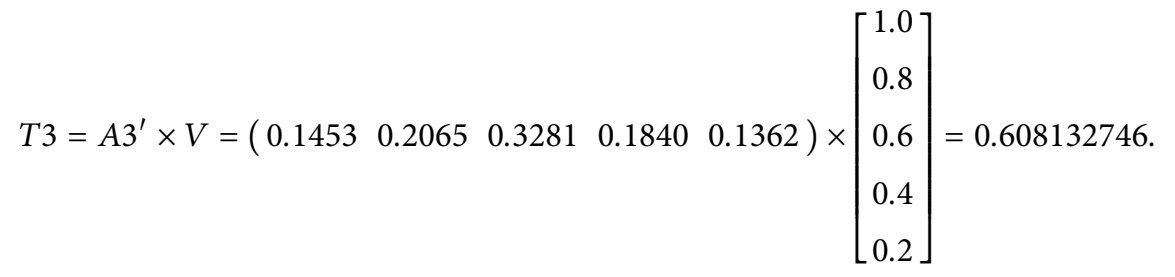

Similarly, according to the above five steps, we conducted fuzzy comprehensive evaluation on $A 1$ venue comprehensive performance, $A 4$ economic performance, $A 5$ venue maintenance, and other first-level indicators. The evaluation scores are shown in Table 7.

6.3.3. Fuzzy Comprehensive Evaluation of Sustainable Postmatch Utilization of Large Stadiums. Based on the quantitative and qualitative index evaluation scores calculated in the above steps, the first-level index evaluation score vector was constructed, and combined with the first-level index weight, the final overall comprehensive evaluation score was obtained.

$$
A=\left(\begin{array}{lllll}
0.6609 & 0.725 & 0.6081 & 0.5681 & 0.6902
\end{array}\right) \times\left[\begin{array}{c}
0.14862 \\
0.29039 \\
0.2176 \\
0.10238 \\
0.24101
\end{array}\right]
$$$$
=0.6656 \text {. }
$$

According to the evaluation results, the evaluation score of the sustainable use of Bengbu Sports Center in Anhui province, China, is 0.6656, which is between 0.8 and 0.6; thus, it can be judged that the sustainable postmatch use of the stadium is "good." Among the first-level index evaluation scores, service level has the highest evaluation score, reaching 0.725, mainly due to the success of the 14th Anhui Provincial Games, bringing a series of small- and mediumsized competitions to make use of the stadium. The activity bearing capacity of the stadium has been effective, but there is room for improvement, and the development of the stadium in terms of commercial activities needs to be further strengthened. The economic performance evaluation score is the lowest, which belongs to the "pass" level. The main reason for this is that business income is small. The stadium has not been market-oriented after the game, and the operation management mode is lagging. It is thus necessary to introduce market mechanism and increase business income. The above evaluation score results are basically consistent with those of other researchers' qualitative analysis, which is in line with the current situation of the use of large-scale sports stadiums in China.

\section{Conclusions}

(1) The evaluation system for the sustainable utilization of large-scale stadiums and gymnasiums in China is to measure the operation and performance of stadiums and gymnasiums, which is constructed by five level indicators, namely, comprehensive performance, service level, environmental performance, economic performance, and maintenance of stadiums and gymnasiums

(2) Based on the fuzzy comprehensive evaluation model, the paper evaluates Bengbu Sports Center in Anhui province, China, and concludes that the sustainable utilization of the stadium is a "good" grade

(3) At present, the postcompetition utilization of large stadiums and gymnasiums in China has some problems, such as outdated system and mechanism, insufficient development power, single industrial chain, and no mature systematic operation

\section{Data Availability}

Data are available from the corresponding author upon request.

\section{Conflicts of Interest}

The authors declare that there are no conflicts of interest regarding the publication of this paper.

\section{Acknowledgments}

This work was supported by the Anhui Province Philosophy and Social Sciences Planning Project (no. AHSKY2016D63), Anhui Education Department Teaching and Research Fund Project (no. 2018jyxm1305), Key Teaching and Research Project of Anhui University of Finance and Economics "The Construction of Teaching Competition" Double Core Teaching Mode of Public Physical Education in Colleges and Universities (acjyzd2019012), and Anhui University of Finance and Economics School-Level Teaching and Research Fund Project (acxkjsjy201803zd and acjyyb2018006). 


\section{References}

[1] China Sport General Administration, "The sixth China sports census data bulletin," 2014, http://www.sport.gov.cn/n16/ n1077/n1467/n3895927/n4119307/7153937.html.

[2] J. Dai, S. Zhang, Y. Tang, X. J. Guo, and Z. H. Ma, "Value orientation and path selection of public sports service system innovation in governance context," China Sports Science, vol. 35, no. 11, pp. 3-12, 2015.

[3] C. Yuanxin and W. Jian, "Current status, constraints and countermeasures of the operation of large-scale sports venues in China," Journal of Shanghai Sport University, vol. 34, no. 5, pp. 17-21, 2010.

[4] China Sport General Administration, "The 13th five-year plan for China sports development," 2016, http://www.sport.gov. cn/n316/n340/c723004/content.html.

[5] M. Manni, A. Petrozzi, V. Coccia, A. Nicolini, and C. Franco, "Investigating alternative development strategies for sport arenas based on active and passive systems," Journal of Building Engineering, vol. 31, Article ID 101340, 2020.

[6] G. Johnson, "The economic impact of new stadiums and arenas on cities," University of Denver Sports \& Entertainment Law Journal, vol. 230, pp. 3-40, 2011.

[7] P. Fabris, "Sports stadiums and arenas showcase sustainability features," Building Design \& Construction, https://schlr.cnki.net/Detail/index/SPQD_01/ SPQDCAF0D3A8DC369B73A27EE0ED25B3A95B, 2018.

[8] A. Thornley, "Urban regeneration and sports stadia," European Planning Studies, vol. 10, no. 7, pp. 813-818, 2002.

[9] L. Roger and R. L. Kemp, Cities and Sports Stadium:A Planning Handbook, Mc Farland Press, Jefferson, NC, USA, 2009.

[10] B. A. Griffin, C. Eibner, C. E. Bird et al., "The relationship between urban sprawl and coronary heart disease in women," Health \& Place, vol. 20, no. 3, pp. 51-61, 2013.

[11] I. Jewell and A. G. Leblanc, "Systematic review of the health benefits of physical activity and fitness in school-aged children and youth," International Journal of Behavioral Nutrition and Physical Activity, vol. 7, no. 1, pp. 1-16, 2010.

[12] M. V. D. Hurk and K. Verhoest, "On the fast track? Using standard contracts in public-private partnerships for sports facilities: a case study," Sport Management Review, vol. 20, pp. 226-239, 2017.

[13] J. Norman, H. L. Maclean, and C. A. Kennedy, "Comparing high and low residential density: life-cycle analysis of energy use and greenhouse gas emissions," Journal of Urban Planning and Development, vol. 132, no. 1, pp. 10-21, 2006.

[14] S. Winkelman, A. Bishins, and C. Kooshian, "Planning for economic and environmental resilience," Transportation Research Part A: Policy and Practice, vol. 44, no. 8, pp. 575586, 2010.

[15] J. Burke and J. Shang, "Post event sustainability: London 2012 Olympics," World Archit, vol. 8, pp. 92-95, 2015.

[16] B. Hanway and S. Sun, "London 2012 olympic park masterplan and legacy," Landscape Architecture, vol. 3, pp. 102$110,2012$.

[17] C. Santo, "The economic impact of sports stadiums: recasting the analysis in context," Journal of Urban Affairs, vol. 27, no. 2, pp. 177-192, 2010.

[18] B. R. Muijsson, "Increasing profitability of multifunctional sport stadiums: a research on using a decision support model to increase profitability and feasibility of multifunctional sport stadiums," 2015, http://resolver.tudelft.nl/uuid:145856b5487b-4a66-8cca-9871228f01fe.
[19] Y. X. Ding and L. Zhang, "Application research on TOT model used to public sports stadium under the background of ownership and operation separation," Journal of Beijing Sport University, vol. 40, no. 2, pp. 24-29, 2017.

[20] A. Amna and F. Salim, "Sports arena development: scalability impact on urban fabric integration," Architecture Research, vol. 6 , no. 6, 2016.

[21] J. L. Crompton, D. R. Howard, and T. Var, "Financing major league facilities: status, evolution and conflicting forces," Journal of Sport Management, vol. 17, no. 2, pp. 156-184, 2010.

[22] L. Rebeggiani, "Public vs. private spending for sports facilities-the case of Germany," Journal of Public Finance and Management, vol. 6, no. 3, pp. 395-435, 2006.

[23] H. Westerbeek, P. Emery, and P. Turner, Managing Sport Facilities and Major Events, Routledge, New York, NY, USA, 2006.

[24] Y. Hongyan and Z. Xu, "Research on sustainable building innovation strategy based on life cycle analysis," Architecture Science, vol. 8, pp. 9-13, 2007.

[25] R. Apanavičienè, D. Ala, T. Baltramonaitis, and V. Maliene, "Sustainability aspects of real estate development: Lithuanian case study of sports and entertainment arenas," Sustainability, vol. 7, no. 6, 2015.

[26] Y. 1. Li, "Research on sustainable building innovation strategy for sports venues in China," Journal of Beijing Sport University, vol. 36, no. 03, pp. 39-43, 2013.

[27] L. Lei, S. H. Xiao, Q. Fu, and L. Chen, "Operation management of large-scale sports venues in China: model selection and path arrangement," Journal of Beijing Sport University, vol. 36, no. 10, pp. 10-15, 2013. 